\title{
Torsion of a seminoma in an intrascrotal testis: A case report and review of the literature
}

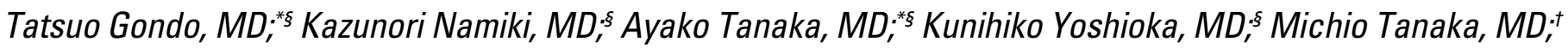 \\ Hidenobu Yamamoto, MD; ${ }^{*}$ Masaaki Tachibana, $M D^{\varsigma}$
}

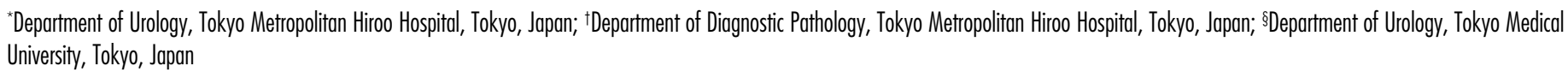

Cite as: Can Urol Assoc J 2013;7:E108-E1 11. http://dx.doi.org/10.5489/cuaj.248

\section{Abstract}

An intrascrotal testicular torsion with malignant testicular tumour is extremely rare. We report a case of a 26-year-old male who was diagnosed with testicular torsion by magnetic resonance imaging and with testicular seminoma after orchiectomy. Through this case, we found that if the possibility of testicular torsion remains during the diagnosis of acute scrotum cases, additional examination adding to colour Doppler sonography should be performed. Furthermore, we should be aware of the possibility of testicular tumours during the diagnosis and treatment of acute scrotums. If the affected testis is preserved in the treatment of testicular torsion, a postoperative examination by ultrasound and/or tumour markers for the remaining testis is essential to confirm the absence of testicular tumour.

\section{Introduction}

Although various medical devices have been developed in recent years, some testicular torsion is still misdiagnosed. This is due to the technical factors of diagnosis and to the existence of incomplete torsion. ${ }^{1}$ To confirm a diagnosis of incomplete testicular torsion without surgery is difficult because the symptoms are atypical and the onset is subacute. ${ }^{2}$ In addition, intrascrotal testicular torsion with testicular tumour is extremely rare, while torsion of underscended testis with testicular tumour have been reported.

We describe an unusual case. Our patient presented with incomplete torsion and was histologically diagnosed with testicular seminoma post-surgery.

\section{Case report}

A 26-year-old male visited our clinic with dull pain in the left lower abdomen and scrotum, lasting 2 hours. He had sexual relations with a sex worker 2 weeks before. His temperature was normal and urinary analysis showed normal levels of white blood cells. An ultrasound revealed swelling of the left epididymis, and colour Doppler sonography (CDS) showed no abnormal signs of blood flow into the left testis. We diagnosed left epididymitis and gave him antibiotics. After 3 days, he returned to our clinic because the pain did not go away. An ultrasound showed multifocal hypo-echoic areas in the left testis (Fig. 1). Blood examination showed abnormal elevation of white blood cells $(15200 / \mu \mathrm{L})$, lactate dehydrogenase $(\mathrm{LDH})(888 \mathrm{U} / \mathrm{L})$, and c-reactive protein (CRP) $(9.9 \mathrm{mg} / \mathrm{dL})$. Computed tomography (CT) with contrast medium showed normal arterial blood flow around the left testis, but indicated the possibility of hemorrhage in the left testis (Fig. 2a, Fig. 2b). Magnetic resonance imaging (MRI) suggested twisting of the left spermatic cord on the left epididymis and necrosis in the left testis (Fig. 3). We suspected testicular torsion, and an emergency operation was performed.

During the surgery, we found the left testis twisted at 90 degrees counterclockwise, and the left testis and epididymis swollen and discolored with a blackened appearance (Fig. 4). We had to perform a simple left orchiectomy because the colour of the testis did not come back to normal after de-twisting it. The gross appearance of a section of the resected left testis revealed the hematoma and necrotic testicular tissue (Fig. 5). Immunohistochemistry confirmed viable seminoma cells in the necrotic area of the testis and no syncytiotrophoblastic cells were observed in the tumour tissue (Fig. 6). We measured testicular tumour markers, such as $\beta$-human chorionic gonadotropin ( $\beta$-hCG) and alpha-fetoprotein (AFP), in a serum preoperatively. While the AFP level $(1.9 \mathrm{ng} / \mathrm{mL})$ was within normal limits, the level of the $\beta$-hCG $(0.32 \mathrm{ng} / \mathrm{mL})$ was slightly high. Two weeks after the operation, the level of $\beta$-hCG $(0.17 \mathrm{ng} / \mathrm{mL})$ did not get to normal levels, and we detected para-aortic lymph node metastases on an abdominal CT scan. The patient was finally diagnosed with pT2N2M0 stage IIB testicular seminoma and was treated with cisplatin-based chemotherapy. 


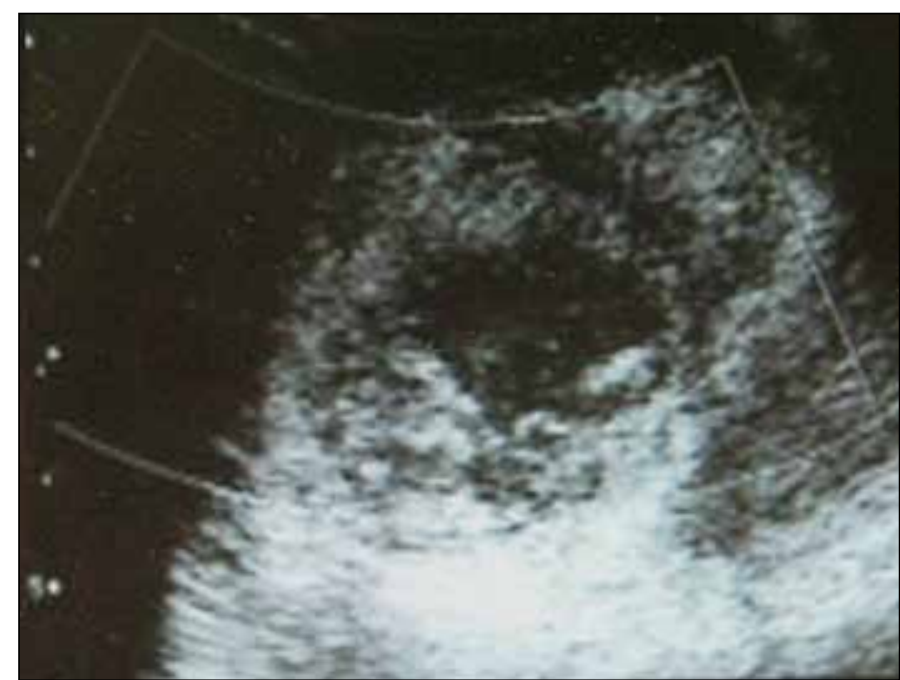

Fig. 1. Ultrasound showed multifocal hypo-echoic areas in the left testis.

\section{Discussion}

Torsion with a rotation of more than $360^{\circ}$ is defined as complete torsion; a rotation less than $360^{\circ}$ is defined as partial or incomplete torsion. ${ }^{3}$ In incomplete torsion, the arterial supply is not completely impeded and can be detected as far as the mediastinum testis. ${ }^{3}$ Because most cases of testicular torsion present with epididymal swelling, incomplete torsion with normal blood flow is sometimes misdiagnosed as epididymitis. ${ }^{4}$ In our case, we could not initially diag-

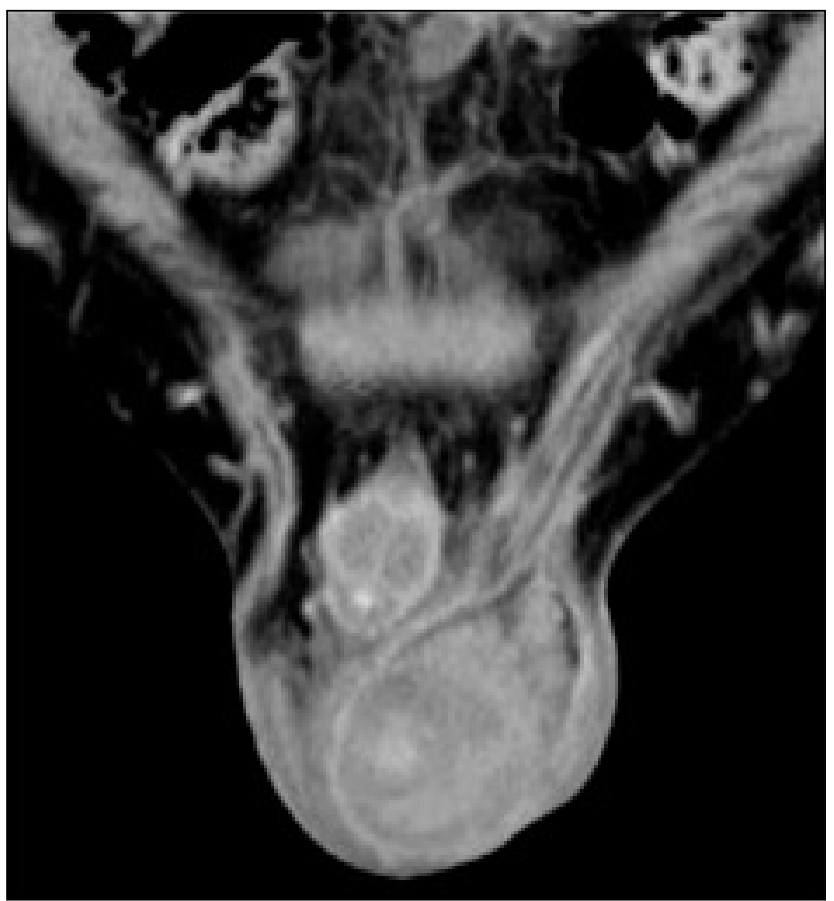

Fig. 2b. Arterial blood flow into the left testis continued to be observed on computed tomography with contrast medium.

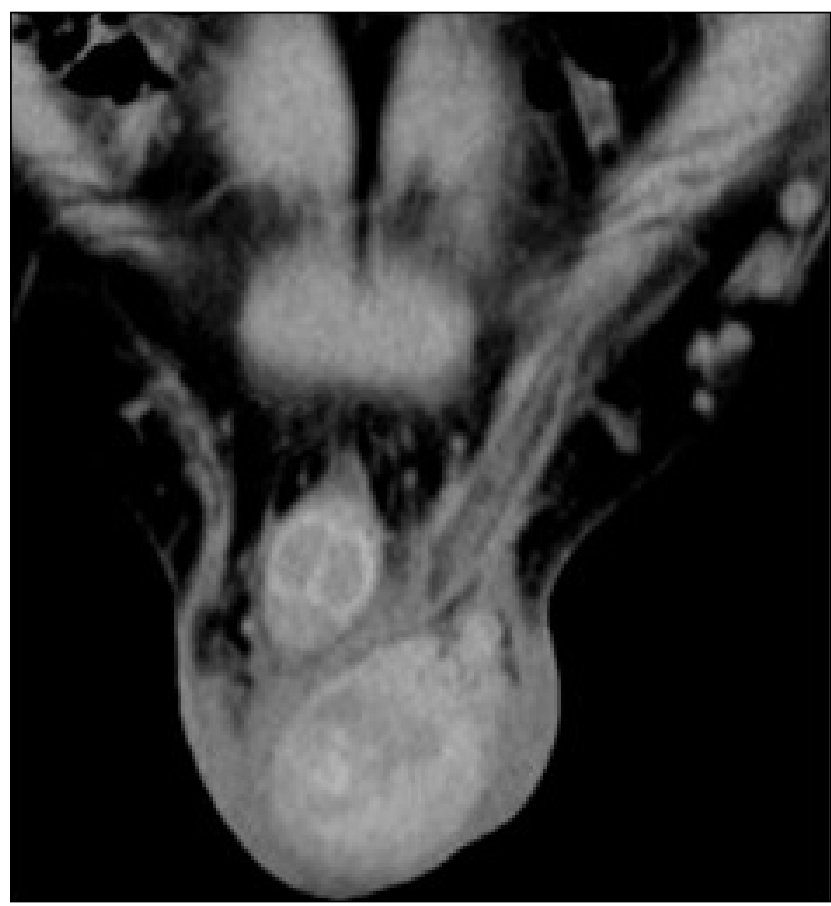

Fig. 2a. Computed tomography revealed swelling of the left testis and epididymis in the high-density area.

nose testicular torsion because the blood flow was preserved by CDS and the epididymal swelling led us to diagnose it as epididymitis. Some authors indicated that the estimation of length and the existence of a twist (whirlpool sign) of the spermatic cord by ultrasonography are valuable to diagnose

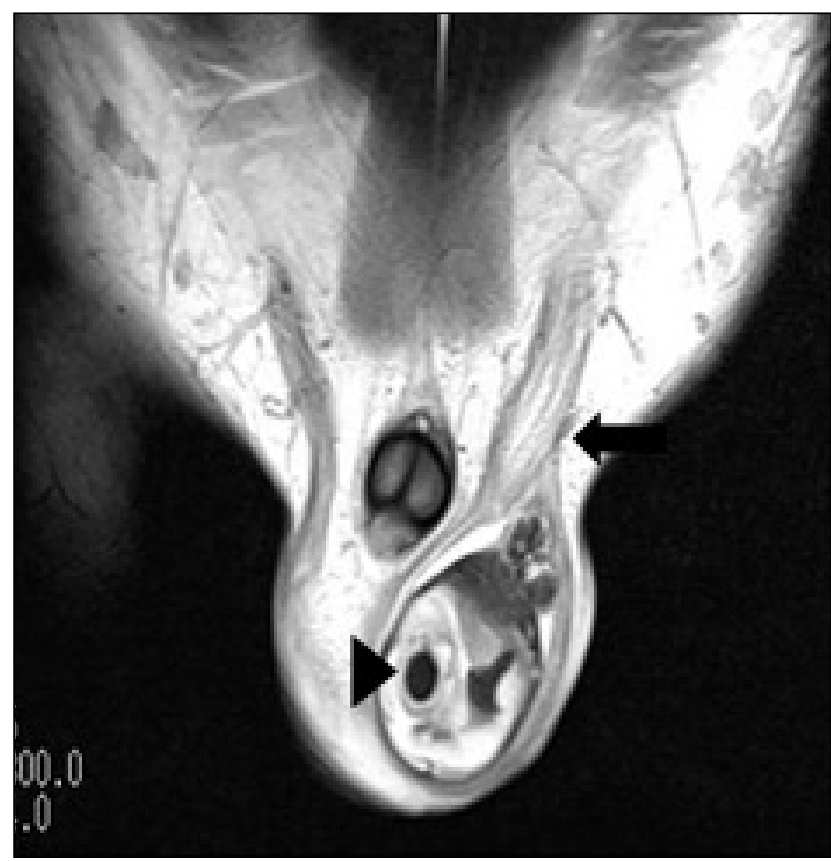

Fig. 3. T2-weighted image in magnetic resonance imaging supported the diagnosis of necrosis in the left testis (arrow head) and twisting of the left spermatic cord (whirlpool sign) upon the left epididymis (arrow). 


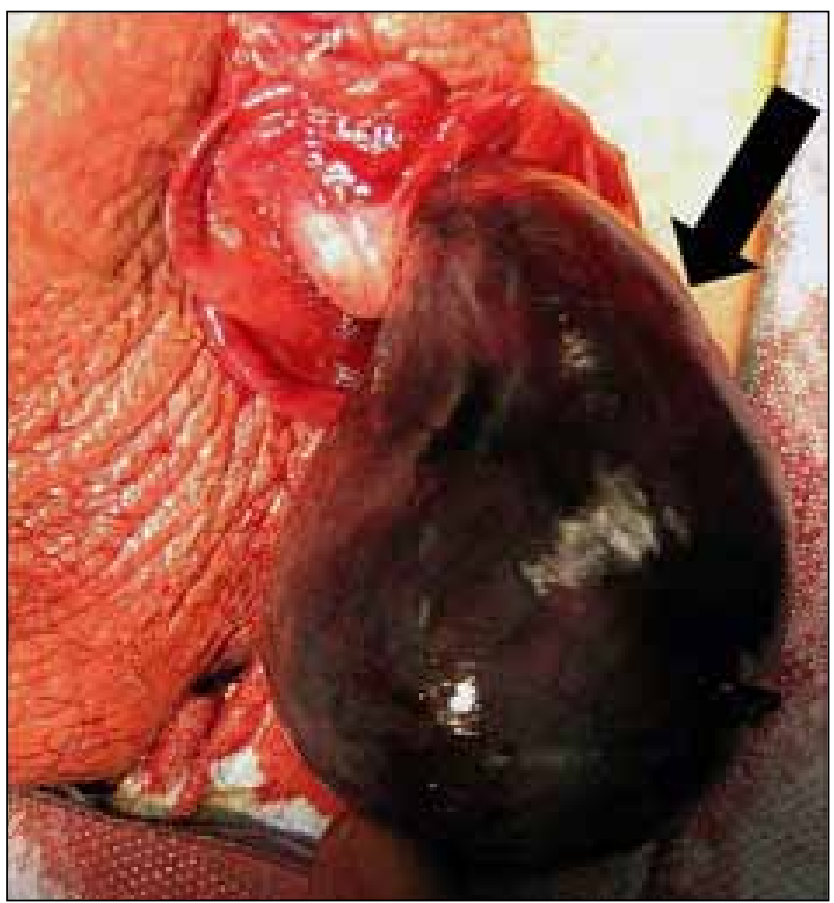

Fig. 4. The left testis was twisted 90 degrees counterclockwise, and the left testis and epididymis (black arrow) had become swollen and discolored with a blackened appearance.

incomplete torsion. ${ }^{5,6}$ Cassar and colleagues ${ }^{7}$ and Gotto and colleagues ${ }^{2}$ report the usefulness of spectral Doppler sonography and MRI to diagnose incomplete testicular torsion, respectively. Although MRI has thus far been regarded as a useful tool to diagnose testicular torsion because of its capability of detecting testicular necrosis, ${ }^{8}$ it is possible that MRI can identify a twist. Indeed, in our case, this was true. The MRI suggested that the spermatic cord was twisted. MRI should be carried out if circumstances permit.

An intrascrotal testicular torsion with malignant testicular tumour is extremely rare. To our knowledge there have been only 5 cases in the English literature to date (Table 1). ${ }^{9-12}$ In our case, the affected left testis was removed because its colour did not go back to normal, yet the left spermatic cord remains. We were concerned with local recurrence and the possibility of hematogenous metastasis due to releasing the twist of the left testis. The possibility of a tumour in testicular torsion case may have serious adverse consequences. Cos and colleagues ${ }^{10}$ and Perez ${ }^{11}$ have reported intratesticular torsion with testicular malignant tumour which was diagnosed postoperatively by histopathological examination. These reports suggested that it is difficult to diagnose testicular tumours in cases of testicular torsion preoperatively or intraoperatively. Seaman and colleagues suggest that the biopsy and frozen section examination should be performed when a tumour is suspected, but the authors also mention admit that edema and inflammation make it difficult to evaluate affected testis. ${ }^{12}$ Therefore, we always need to be aware

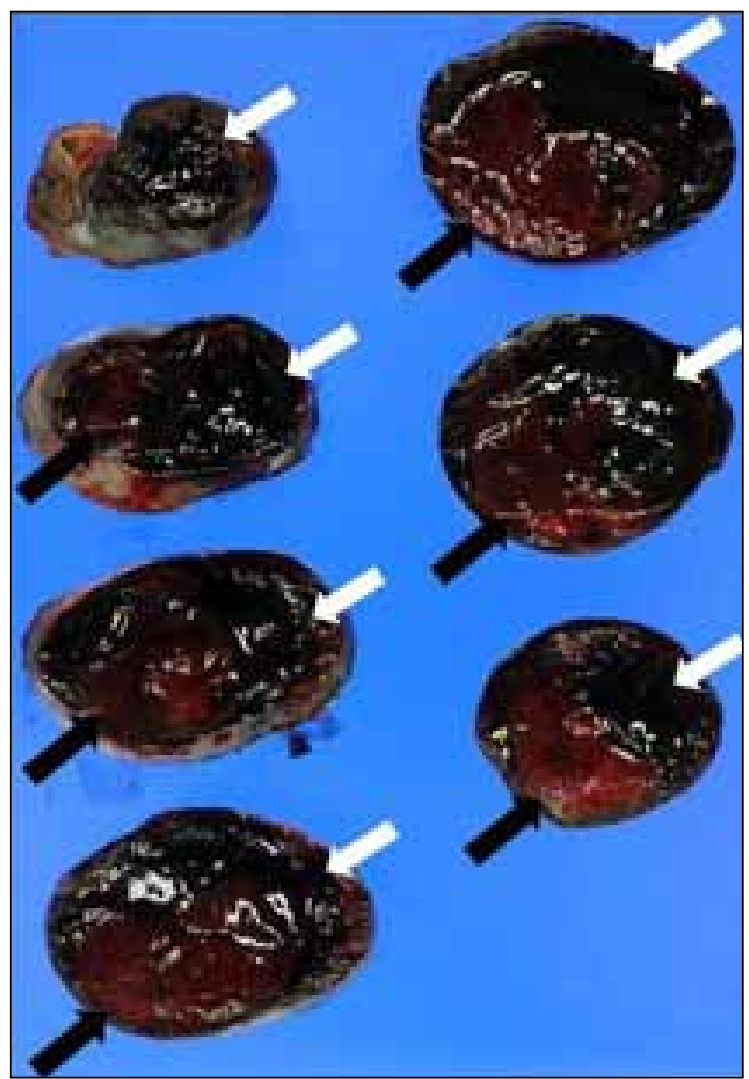

Fig. 5. The gross appearance of a section of the resected left testis revealed hematoma (white arrow) and necrotic testicular tissue (black arrow).

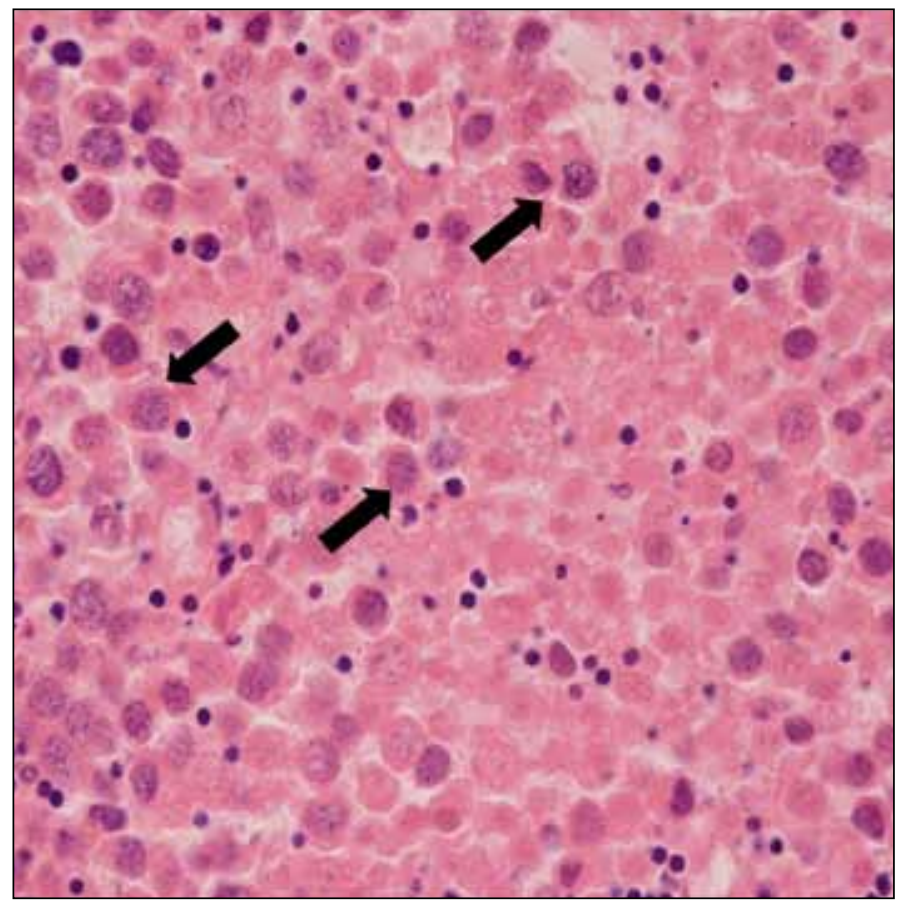

Fig. 6. Microscopic findings (hematoxylin-eosin, original magnification $\times 400$ ) demonstrated viable seminoma cells (arrow) in the necrotic area of the left testis. The border between the tumour and necrotic testicular tissue was unclear. 


\begin{tabular}{lccccc}
\hline \multicolumn{5}{l}{ Table 1. Characteristics of 6} & reported cases of testicular malignant tumour presenting intrascrotal testicular torsion \\
\hline Case no. & Year & Authors & Patient age & Location & Pathology \\
\hline 1 & 1943 & Mohardt & 26 & $\mathrm{R}$ & Embryonal carcinoma \\
2 & 1983 & Cos et al. ${ }^{10}$ & 28 & $\mathrm{R}$ & Seminoma \\
3 & 1983 & Cos et al. ${ }^{10}$ & 19 & $\mathrm{R}$ & Teratocarcinoma \\
4 & 1990 & Perez ${ }^{11}$ & 18 & $\mathrm{~L}$ & Mixed germ cell tumour \\
5 & 1993 & Seaman et al. ${ }^{12}$ & 52 & $\mathrm{~L}$ & Seminoma \\
6 & 2011 & Present case & 26 & $\mathrm{~L}$ & Seminoma \\
\hline
\end{tabular}

of the possibility of testicular tumours during diagnosis and treatment for acute scrotums.

A pathological examination is essential for patients who have had orchiectomy due to testicular torsion. Furthermore, the examination of preoperative and postoperative tumour markers may help detect a testicular tumour because the pathological examination for necrotic testis may be difficult to confirm the presence of a tumour lesion. If the affected testis was preserved, a postoperative examination by ultrasound and/or tumour markers for the remaining testis is essential to confirm the absence of testicular tumour.

\section{Conclusion}

We report on an extremely rare case of testicular seminoma with intrascrotal testicular torsion. We should be aware of the possibility of testicular tumours during diagnosis and treatment for acute scrotums, although the association of torsion and tumour is rare.

Competing interests: None declared.

This paper has been peer-reviewed.

\section{References}

1. Bentley DF, Ricchiuti DJ, Nasrallah PF, et al. Spermatic cord torsion with preserved testis perfusion: initial anatomical observations. J Urol 2004;172:2373-6. http://dx.doi.org/10.1097/01. ju.0000145527.08591.27

2. Gotto GT, Chang SD, Nigro MK. MRI in the diagnosis of incomplete testicular torsion. $B r J$ Radiol 2010;83:e105-7. http://dx.doi.org/10.1259/bir/95900989

3. Hörmann M, Balassy C, Philipp M0, et al. Imaging of the scrotum in children. Eur Radiol 2004;14:974-83. http://dx.doi.org/10.1007/s00330-004-2248-x

4. Nussbaum Blask AR, Rushton HG. Sonographic appearance of the epididymis in pediatric testicular torsion. AJR Am J Roentgenol 2006;187:1627-35. http://dx.doi.org/10.2214/AJR.05.0461

5. Baud C, Veyrac C, Couture A, et al. Spiral twist of the spermatic cord: a reliable sign of testicular torsion. Pediatr Radiol 1998;28:950-4. http://dx.doi.org/10.1007/s002470050507

6. Kalfa N, Veyrac $C$, Baud C, et al. Ultrasonography of the spermatic cord in children with testicular torsion: impact on the surgical strategy. J Urol 2004;172:1692-5. http://dx.doi.org/10.1097/01. ju.0000138477.85710.69

7. Cassar S, Bhatt S, Paltiel HJ, et al. Role of spectral Doppler sonography in the evaluation of partial testicular torsion. J Ultrasound Med 2008;27:1629-38.

8. Watanabe $Y$, Nagayama M, Okumura A, et al. MR imaging of testicular torsion: features of testicular hemorrhagic necrosis and clinical outcomes. J Magn Reson Imaging 2007;26:100-8. http://dx.doi. org/10.1002/imri.20946

9. Mohardt JH. Torsion of spermatic cord with unsuspected testicular tumor. Illinois Med J 1943;84:389

10. Cos L, Peartree R, Descalzi M, et al. Torsion of intrascrotal malignant testis tumors. J Urol 1983;130:145-7.

11. Perez J. Testicular tumor presenting with torsion of the testicle. J Urol 1990;144:995-6.

12. Seaman E, Sawczuk I. Testis tumor in an adult presenting with torsion of testis. Urology 1993;42:453-4. http://dx.doi.org/10.1016/0090-4295(93)90385-N

Correspondence: Dr. Tatsuo Gondo, Department of Urology, Tokyo Metropolitan Hiroo Hospital, 2-3410 Ebisu, Shibuya-ku, Tokyo, Japan 150-0013; fax: +81-3-3446-5419; gonta@tokyo-med.ac.jp 